\title{
Cervical spinal cord injection of epidural corticosteroids: Comprehensive longitudinal study including multiparametric magnetic resonance imaging
}

\section{Citation}

Cohen-Adad, Julien, Bradley Buchbinder, and Anne Louise Oaklander. 2012. “Cervical Spinal Cord Injection of Epidural Corticosteroids: Comprehensive Longitudinal Study Including Multiparametric Magnetic Resonance Imaging." Pain 153 (11) (November): 2292-2299. doi:10.1016/j.pain.2012.07.028.

\section{Published Version}

doi:10.1016/j.pain.2012.07.028

\section{Permanent link}

http://nrs.harvard.edu/urn-3:HUL.InstRepos:34627333

\section{Terms of Use}

This article was downloaded from Harvard University's DASH repository, and is made available under the terms and conditions applicable to Other Posted Material, as set forth at http:// nrs.harvard.edu/urn-3:HUL.InstRepos:dash.current.terms-of-use\#LAA

\section{Share Your Story}

The Harvard community has made this article openly available.

Please share how this access benefits you. Submit a story.

\section{Accessibility}




\title{
Cervical spinal cord injection of epidural corticosteroids; comprehensive longitudinal study including multiparametric MRI
}

\author{
Julien Cohen-Adad, Ph.D.a,b,e, Bradley Buchbinder, M.D. ${ }^{b, c}$, and Anne Louise Oaklander, \\ M.D., Ph.D $\mathbf{D}^{\mathrm{b}, \mathrm{d}}$ \\ ${ }^{a}$ A.A. Martinos Center for Biomedical Imaging, Department of Radiology, Massachusetts General \\ Hospital, Charlestown, MA, USA \\ bHarvard Medical School, Boston, MA, USA \\ 'Department of Radiology, Division of Neuroradiology, Massachusetts General Hospital, Boston, \\ MA, USA \\ ${ }^{\mathrm{d} D e p a r t m e n t s}$ of Neurology and Neuropathology, Massachusetts General Hospital, Boston, MA, \\ USA \\ eDepartment of Electrical Engineering, Ecole Polytechnique de Montreal, QC, Canada
}

\begin{abstract}
Despite widespread use, the efficacy of epidural corticosteroid injections (ESI) for osteoarthritisassociated neck or radicular pain remains uncertain, so even rare serious complications enter into discussions about use. However various factors impede investigation and publication of serious adverse events. To that end, we developed new magnetic resonance imaging (MRI) techniques for spinal cord white-matter quantification and employed best-available physiological tests to characterize a cervical spinal cord lesion caused by inadvertent intramedullary injection of DepoMedrol. A 29-year-old woman with mild cervical osteoarthritis had 2 years of headache and neck pain (concussion and whiplash) after two minor motor-vehicle accidents. During C5-6 ESI, she developed new left-sided motor and sensory symptoms and MRI demonstrated a new left dorsal spinal cord cavity. Mild left-sided motor and sensory symptoms have persisted for more than 2 years, during which time we performed serial neurological examinations, standard electrodiagnostics, somatosensory evoked potentials, and transcranial measurement of corticospinal central motor conduction time (CMCT). We used 3 tesla MRI with a 32-channel coil developed for high-resolution cervical spinal cord structural imaging, diffusion tensor imaging (DTI) and magnetization transfer (MT). $\mathrm{T}_{2}{ }^{*}$-weighted signal, DTI and MT metrics showed delayed spread of the lesion across four vertebral levels rostrally, consistent with Wallerian degeneration within the ascending left dorsal columns. However only CMCT metrics detected objective correlates of her left hemiparesis and bilateral hyperreflexia. DTI and MT metrics may better distinguish between post-traumatic demyelination and axonal degeneration than
\end{abstract}

C 2012 International Association for the Study of Pain. Published by Elsevier B.V. All rights reserved

Corresponding author: Julien Cohen-Adad, Ph.D., Department of Electrical Engineering, Ecole Polytechnique de Montreal, 2900 Edouard-Montpetit Bld, Montreal, QC, H3T 1J4, Canada, Tel: 514-340-4711; Fax: 514-340-4611, jcohen@ polymtl.ca.

Conflict of Interest Statement

There are no conflicts of interest to report.

Publisher's Disclaimer: This is a PDF file of an unedited manuscript that has been accepted for publication. As a service to our customers we are providing this early version of the manuscript. The manuscript will undergo copyediting, typesetting, and review of the resulting proof before it is published in its final citable form. Please note that during the production process errors may be discovered which could affect the content, and all legal disclaimers that apply to the journal pertain. 
conventional MRI. These tests should be considered to better characterize similar spinal cord injuries.

\section{Introduction}

Two prospective [18,49] and a half-dozen retrospective studies (vide infra) find complications rare but relatively more frequent after cervical than lumbar epidural-steroidinjection (ESI) [47]. Intramedullary injection can only complicate cervical or the rare thoracic injections because lumbar-ESI is performed below the conus medullaris. Usuallyminor complications of cervical-ESI include vomiting, flushing, hypotension, neck pain, dural puncture causing intracranial hypotension, and systemic corticosteroid effects [1,14]. Variably severe complications include subdural and intra-arterial injection, abscesses and granulomas, meningitis, osteomyelitis, plus nerve-root injury from needle, injectate, infection, or scarring. Spinal cord and brain injury are universally considered serious adverse events. Cervical spinal cord injury (SCI) is considered particularly serious because of potential involvement of the arms as well as the legs (quadriparesis), cardiorespiratory compromise, and sudden death.

In this article we present a case of intramedullary injection during interlaminar ESI procedure. Literature search in 2011 revealed some dozen published cases of cervical-SCI after interlaminar approach to cervical-ESI [1], plus several cases after nerve-root-sheath injections. Serious complications include two epidural abscesses (approach unspecified, presumed interlaminar) [23,50], six epidural hematomas between 1996 and 2005 (reviewed in [1]) and one subdural hematoma [38], with outcomes ranging between full recovery to paraplegia. We identified only 3 prior cases of injection into or through the cervical cord during cervical-ESI; one from transforaminal approach [28] and two from interlaminar approach 1-1.5 cm lateral to the midline [22]. These two occurred in sedated patients and prompted recommendation to keep patients alert and able to report any new symptoms [22].

For new neurological complaints after spinal injection, imaging, which defines diagnosis and treatment, should be performed urgently and compared to pre-procedure studies (Figure 1). Conventional magnetic resonance imaging (MRI), including $\mathrm{T}_{1}$-weighted $\left(\mathrm{T}_{1} \mathrm{w}\right), \mathrm{T}_{2} \mathrm{w}$ and $\mathrm{T}_{2} * \mathrm{~W}$ sequences identify necrosis, edema, ischemia and compression, but have low specificity and sensitivity for white-matter tract integrity.

Advanced MRI techniques more specific to white matter structure have altered understanding of common brain diseases including stroke and multiple sclerosis [34,45], however they are not yet common in spinal cord imaging. Magnetization transfer (MT) is sensitive to demyelination [33,36], while diffusion tensor imaging (DTI) is sensitive to both demyelination and axonal degeneration [43]. Their relative value is debated [32,51], but combining them may improve spinal cord assessment $[8,37]$. Here, we evaluated the utility of multi-parametric MRI in SCI by combining $\mathrm{T}_{1} \mathrm{w}, \mathrm{T}_{2} \mathrm{w}, \mathrm{T}_{2}{ }^{*} \mathrm{w}$, DTI and MT. We developed a new coil [11] that enables very high resolution (300 microns). Radiological examination was correlated with serial neurological examination and comprehensive physiological tests of spinal cord integrity.

\section{Methods}

\subsection{Design}

Using an approved IRB protocol, clinical and radiological data were collected from a 29 year-old woman after cervical ESI. In addition to the experimental MRI technique developed for this case, she was also evaluated with conventional diagnostic MRI and all available tests of integrity of peripheral and spinal motor and sensory pathways, specifically 
conventional electromyography and nerve conduction study, upper- and lower-limb somatosensory evoked potentials, and measurement of upper- and lower-limb central motor conduction time (CMCT) using transcranial magnetic stimulation (TMS) of the motor cortex [16]. Comprehensive medical records from before and post-injury records for up to 28 months were analyzed. Data from other providers were obtained through IRB-approved retrospective medical-record review.

\subsection{Subject Case History}

This young woman had two low-speed motor vehicle accidents in 2008 that caused whiplash and concussion, including chronic neck pain and cervicogenic headache. These were treated unsuccessfully by outside practitioners with physical therapy, chiropractic manipulation, multiple medications and multiple injections. Two diagnostic local-anesthetic medial-branch blocks at $\mathrm{C} 2$ and $\mathrm{C} 3$ gave temporary pain relief so she underwent radiofrequency ablation of the primary ramus of the left and right $\mathrm{C} 2$ and $\mathrm{C} 3$ roots. This improved left occiput pain but worsened right occiput pain. This was treated with local-anesthetic blocks of the greater and lesser occipital nerves (side unspecified) and two sets of injections of local anesthetic and methylprednisolone acetate into 12 bilateral trigger points at one-month interval. The plan was for 3 subsequent cervical-ESI.

The first ESI was performed on 11/23/09 at the C4-5 intervertebral space. $1.5 \mathrm{cc}$ of $1 \%$ lidocaine was administered subcutaneously with a $1.5^{\prime \prime} 25 \mathrm{G}$ needle. A $20 \mathrm{G}$ Tuohy needle was then advanced via a midline approach under fluoroscopic guidance using the hangingdrop technique. Two cc of Omnipaque-180 were injected for fluoroscopic visualization prior to injecting $80 \mathrm{mg}$ of Depo-Medrol (methylprednisolone acetate injectable suspension; Pharmacia and Upjohn Division of Pfizer, New York, NY) in an unspecified volume after negative aspiration. This was well tolerated, and ESI was repeated on 12/16/09 at the C5-6 intervertebral space after subcutaneous administration of $1.5 \mathrm{cc}$ of $1 \%$ lidocaine with a $1.5^{\prime \prime}$ $25 \mathrm{G}$ needle via a midline approach. After negative aspiration, an $18 \mathrm{G}$ Tuohy needle was used to inject $1 \mathrm{cc}$ of Omnipaque-180 and then $2 \mathrm{cc}$ of preservative-free normal saline containing $80 \mathrm{mg}$ of Depo-Medrol. The records document that the patient complained of sudden left arm and leg muscle spasms after the subcutaneous lidocaine; these remitted and the procedure was completed. Post-procedure examination documented that "sensation was diminished on the left side of her body from her elbow down her left arm and down the trunk from the shoulder through her left leg and foot. Tone was increased in the upper left and lower extremity. Arm and leg reflexes were not tested; Babinsky (sic) reflex was negative." $500 \mathrm{cc}$ of normal saline and $2 \mathrm{mg}$ of midazolam were administered intravenously. Between 20-45 minutes post-procedure, the tone and sensation in her left hand and then left leg were reported to normalize. She was discharged to home with a Medrol Dosepak reporting only sensory loss in the left lower extremity between the groin and knee. Review of the fluoroscopic records by the proceduralist reported contrast in the epidural space without intrathecal or intravascular spread.

On the following day the patient went to the Emergency Department of an outside hospital because of left-sided weakness and sensory abnormalities. Conventional cervical MRI (Figure 1B) identified a linear $\mathrm{T}_{2}$ hyperintensity within the C5-6 left dorsal cord that had not been present on the cervical MRI of 10/15/2009 (Figure 1A). This prompted admission to the hospital and examination identified left foot-drop that was attributed to acute cervical myelopathy. This diagnosis was treated with intravenous dexamethasone and the patient was transferred to the Massachusetts General Hospital Neurology service. Here, neurological examination on 12/19/2009 identified left-only weakness of flexion and extension at the hip $(4+/ 5)$, knee (4/5), and foot $(4+/ 5)$. The sensory and reflex exams were normal and her gait had excess knee elevation consistent with foot drop (weakness of foot dorsiflexion). On 12/20/2009 neurological examination corroborated this weakness and documented reduced 
left-leg temperature sensation. Flexion/extension neck X-rays were normal and cervical MRI (not shown) documented the prior mild degenerative changes and a $2 \mathrm{~mm}$-diameter, $\mathrm{T}_{2^{-}}$ hyperintense, non contrast-enhancing, signal in the posterior cord to the left of midline extending between the C5-6 level and mid C7. On 12/22/2009 examination revealed mild sensory deficit in the C5 dermatome of the left upper extremity and $4^{\text {th }}$ and $5^{\text {th }}$ finger, markedly reduced touch sensation from the mid-abdomen down to her knee and mild loss of touch on the left calf and bottom of left foot. Proximal and distal strength was $3+/ 5$ in the left leg, reflexes were $3+$, more brisk on the left, and rectal tone was normal. She was discharged to home with outpatient follow-up.

At 6 weeks post-injury, repeat conventional MRI (not shown) revealed a slightly larger (3 $\mathrm{mm}$ diameter) C5-6 CSF-intensity cavity. Examination at 8 weeks post-injury showed that she used an ankle-foot orthotic and cane to walk, had 5-/5 left-arm weakness, 4/5 left-leg weakness with foot drop, and early left-leg spasticity without Babinski reflex or ankle clonus. She reported onset of sharp pain and tingling radiating distally along her left arm and leg. She denied bladder or bowel changes. Her recovery was complicated by depression requiring hospitalization.

At 7.5 months post-injury her left hemiparesis persisted and she reported new occipital numbness (sensory loss) triggered by neck extension and relieved by neutral positioning of her head. With the prolonged neck extension of MRI, even her ears became numb, a phenomenon interpreted as similar to l'Hermitte's sign. Sensory testing with a pin documented mild bilateral occipital sensory loss with neutral neck position, which worsened and spread to the vertex during neck extension. Her reflexes were bilaterally brisk below the jaw, more so in the legs and on the left, with a left-only Babinski reflex.

At 12.5 months post-injury constant headache, left foot drop and intermittent occipital numbness persisted and intermittent left leg and foot muscle cramps along with left hand tingling and "slowness". Examination found left-only reduced occipital pin sensation, mild left-leg increased tone and mild distal-predominant left-sided weakness in her upper and lower extremities. Her reflexes remained bilaterally brisk in the legs and on the left, with both plantar reflexes flexor. At 16 months post-injury the above signs and symptoms persisted (Figure 2). Walking had improved with physical therapy and baclofen but she still used an ankle-foot orthotic and cane, and left foot and toe flexion remained weak. She still reported patchy sensory loss affecting her entire left leg up to the hip. She noted a "hypersensitive" spot on her left instep. At 28 months post-injury her examination was unchanged.

\subsection{Radiological Methods}

The subject underwent two MRI sessions: at 32 weeks and at 51 weeks post-injury. We used a 3T system (Tim Trio, Siemens Healthcare) with a custom-made 32-channel head/spine receive coil [11]. The coil was designed to optimize spatial resolution (due to a two-fold increase in sensitivity compared with the standard coil) and low susceptibility-related distortions in DTI (due to higher achievable acceleration factors). The 48-minute protocol included:

1. Sagittal $3 \mathrm{D} \mathrm{T}_{1} \mathrm{w}$ magnetization-prepared rapid acquisition with multiple gradient echoes [48]. TR/TI $=2530 / 1200 \mathrm{~ms}, \mathrm{TE}=[1.8 ; 3.7 ; 5.7 ; 7.6] \mathrm{ms}$, flip angle $=7^{\circ}$, field of view $(\mathrm{FOV})=230 \times 230 \mathrm{~mm}^{2}$, voxel size $=0.8 \times 0.8 \times 0.8 \mathrm{~mm}^{3}$, bandwidth $(\mathrm{BW})=651 \mathrm{~Hz} / \mathrm{pix}$.

2. Sagittal $\mathrm{T}_{2} \mathrm{w}$ turbo spin echo ( $\left.2 \mathrm{D} \mathrm{TSE}\right)$. TR/TE $=3500 / 101 \mathrm{~ms}$, flip angle $=160^{\circ}$, FOV $=220 \times 220 \mathrm{~mm}^{2}, 0.7 \times 0.7 \times 3 \mathrm{~mm}^{3}, \mathrm{BW}=260 \mathrm{~Hz} / \mathrm{Pix}$. 
3. Axial $\mathrm{T}_{2} * \mathrm{w}$ multiecho fast low angle shot $(2 \mathrm{D}$ FLASH). TR/TE $=781 / 17 \mathrm{~ms}, \mathrm{FOV}$ $=192 \times 192 \mathrm{~mm}^{2}, 0.5 \times 0.5 \times 3 \mathrm{~mm}^{3}$, flip angle $=30^{\circ}, \mathrm{R}=3$ acceleration factor, $\mathrm{BW}=$ $260 \mathrm{~Hz} /$ pix, 3 repetitions. During the second session (week 51) we also acquired images at $0.3 \times 0.3 \mathrm{~mm}$ in-plane resolution.

4. Axial $\mathrm{T}_{2} \mathrm{w} 2 \mathrm{D}$ TSE. TR/TE $=2000 / 102 \mathrm{~ms}$, flip angle $=150^{\circ}, \mathrm{FOV}=200 \times 200$ $\mathrm{mm} 2,0.6 \times 0.6 \times 3 \mathrm{~mm}^{3}, \mathrm{R}=3, \mathrm{BW}=284 \mathrm{~Hz} / \mathrm{Px}, 3$ repetitions.

5. Axial diffusion-weighted echo planar imaging (EPI). Slices were centered in the middle of vertebral bodies to limit susceptibility artifacts [9] and covered C2 to T2. $\mathrm{TR} / \mathrm{TE}=2020 / 118 \mathrm{~ms}, \mathrm{FOV}=83 \times 83 \mathrm{~mm}^{2}, 0.6 \times 0.6 \times 5 \mathrm{~mm}^{3}, \mathrm{R}=2,30$ diffusion gradient directions, b-value $=700 \mathrm{~s} / \mathrm{mm}^{2}, \mathrm{BW}=758 \mathrm{~Hz} / \mathrm{Pix}$, cardiac gating, 4 repetitions. To minimize ghosting saturation bands were positioned anteriorly and posteriorly to the spinal cord.

6. Proton density weighted $2 \mathrm{D}$ FLASH with and without $\mathrm{MT}$ pulse. $\mathrm{TR} / \mathrm{TE}=$ $1070 / 2.52 \mathrm{~ms}, \mathrm{FOV}=204 \times 192 \mathrm{~mm}^{2}, 0.6 \times 0.6 \times 5 \mathrm{~mm}^{3}$, flip angle $=60^{\circ}, \mathrm{BW}=313$ $\mathrm{Hz} / \mathrm{Pix}$, Gaussian MT pulse: duration=9984 s, frequency offset $=1200 \mathrm{~Hz}$.

\subsection{MRI Data processing}

Structural images (axial $\mathrm{T}_{2} * \mathrm{w}$ and $\mathrm{T}_{2} \mathrm{w}$ ) were corrected for patient motion using $3 \mathrm{D}$ rigidbody realignment via FSL FLIRT [24] and then averaged across repetitions. DTI data were split along the $\mathrm{Z}$ direction, motion-corrected on a slice-by-slice basis, and averaged across repetitions. Diffusion tensor and related metrics were estimated voxel-wise. Of all metrics computed, the fractional anisotropy (FA), first eigenvalue (axial diffusivity) and the average of the $2^{\text {nd }}$ and $3^{\text {rd }}$ eigenvalues (radial diffusivity) were further considered for analysis. Proton density weighted volumes with and without MT pulses were co-registered using the non-linear method available in FSL FNIRT [42]. The magnetization transfer ratio (MTR) was computed voxel-wise using $\left[\left(\mathrm{S}_{0}-\mathrm{S}_{\mathrm{MT}}\right) / \mathrm{S}_{0}\right] \times 100$, where $\mathrm{S}_{0}$ and $\mathrm{S}_{\mathrm{MT}}$ are the proton density weighted image without and with the MT pre-saturation pulse, respectively. Cerebrospinal-fluid-normalized MT (MTCSF) was computed by dividing the MT image by the mean CSF intensity of the non-MT image [53]. The mean CSF was computed for each slice independently.

Regions of interest (ROI) were manually defined using geometry-based information [8]. To avoid definitional bias, i.e., circularity induced by defining ROIs based on DTI or MT metrics, ROIs were defined on $\mathrm{T}_{2}$-weighted $\mathrm{b}=0 \mathrm{EPI}$ (for DTI analysis) and proton density weighted images (for MT analysis). Lateral portions of CST and dorsal columns were isolated from $\mathrm{C} 2$ to $\mathrm{T} 3$.

\subsection{Statistical Analysis}

Statistical analysis was performed using Matlab (The Mathworks, MA, USA). Gaussian distribution of DTI and MT metrics was first assessed using a chi-square goodness of fit. This test passed for each metric $(P<0.05)$. Two-way ANOVA was performed for metrics rostral to the primary lesion (C2-C5). The primary lesion was excluded to study whitematter changes distal from the lesion epicenter. Independent variables were: ROIs (dorsal left, dorsal right) and session (week 32 and week 51). Post-hoc analyses included 2-tailed Student's $t$-test paired for vertebral levels to test the effect of laterality (right versus left ROIs). Tests were Bonferroni-corrected for comparison between the two sessions. To test changes between sessions, we computed the ratio between right and left ROIs and performed two-tailed Student's $t$-test paired by vertebral level. 


\section{Results}

\subsection{Non-radiological test results}

Somatosensory evoked potentials were assessed at 13 months post-injury. Stimulation applied over the median nerves at the wrist $(200 \mu \mathrm{s} ; 5 / \mathrm{s}$, minimum 500 superimposed stimuli) elicited normal amplitudes, latencies, inter-peak latencies and no right-left differences. Stimulation applied over the posterior tibial nerves at the medial malleolus (11 $\mathrm{mA}, 200 \mu \mathrm{s} ; 2-5 / \mathrm{s}$, minimum 500 superimposed stimuli) elicited symmetrical normal peripheral and central latencies and was interpreted as normal. Electromyography and nerve conduction study performed at 15 months post-injury excluded potential peripheral causes of her continuing hemiparesis - most importantly nerve-root compression, which commonly accompanies spinal osteoarthritis. Motor and sensory nerve conduction was normal in both legs, as was muscle activity in proximal and distal left-leg muscles.

Central motor conduction time (CMCT) was performed by applying transcranial magnetic stimulation (TMS) to both motor cortices and measuring the latency of spread of compound action potentials down the corticospinal tract to specific muscles. When tested at 16 months post-injury, CMCT was slightly prolonged $(8 \mathrm{~ms}$, normal defined as $5 \pm 2 \mathrm{~ms}$ ) for conduction to both the left and right biceps (innervated by C5-6). Conduction to the first dorsal interossei bilaterally was minimally prolonged on the left $(8 \mathrm{~ms})$ as compared to the right ( $7 \mathrm{~ms}$, normal value $6 \pm 1 \mathrm{~ms}$ ), although the clinical report interpreted all of the above as normal. CMCT was abnormally prolonged to the right $(21 \mathrm{~ms})$ and more so the left (26 $\mathrm{ms}$ ) tibialis anterior muscles (normal $\leq 3 \mathrm{~ms}$ ) interpreted as conduction delay below cervical spinal levels.

\subsection{Radiological results}

3.2.1. Conventional MR imaging-MRI performed one day post-procedure revealed a new linear $\mathrm{T}_{2}$ hyperintense lesion in the left dorsal cord at C5-6 (Figure 1B). Its configuration implicated injectate injury rather than infarction or needlestick alone. It was $1.6^{\prime \prime}$ inches deep to the posterior skin surface, $2.1 \mathrm{~cm}$ in rostrocaudal length, and $0.24 \mathrm{~cm}$ in transverse diameter, with an estimated volume of $0.063 \mathrm{cc}\left(63 \mathrm{~mm}^{3}\right)$ assuming an ellipsoidal shape. At six weeks post-procedure, the lesion was larger in all dimensions. At 32 weeks post-procedure, it had diminished and had become isointense to CSF on strongly $T_{1^{-}}$and $T_{2^{-}}$ weighted images, consistent with evolution of cavitary myelomalacia (Figure 3A,B). New increased $\mathrm{T}_{2}$ - and $\mathrm{T}_{2}{ }^{*}$-weighted signal had appeared within the left dorsal cord rostral to the primary lesion, extending from $\mathrm{C} 5$ to at least $\mathrm{C} 2$ (the rostral margin of the field of view), consistent with Wallerian degeneration of the ascending dorsal-column somatosensory tract (Figure $3 \mathrm{C}, \mathrm{D}$ ). $\mathrm{T}_{2}$ - and $\mathrm{T}_{2}{ }^{*}$-weighted signal were normal caudal to the primary lesion extending to T3 (the inferior margin of the field of view), providing no evidence of Wallerian degeneration of the descending lateral corticospinal tracts. At 51 weeks postprocedure, these findings were unchanged (Figure 3C, D). Gray-white differentiation and lesion conspicuity were greater on $\mathrm{T}_{2} *$-weighted sequences than $\mathrm{T}_{2}$-weighted sequences.

3.2.2. DTI and MT metrics-At 32 and 51 weeks post-injury, DTI and MT findings (Figure 4) correlated with the anatomic distribution of $\mathrm{T}_{2}$ and $\mathrm{T}_{2} *$ signal abnormalities. In a level-by-level analysis from C2 through T3, FA was decreased and MTCSF was increased in the left dorsal cord compared with the right from C2 to C5 (i.e., rostral to the primary lesion), while these dorsal cord metrics were symmetric from $\mathrm{C} 7$ to $\mathrm{T} 3$. The same trends were observed at weeks 32 and 51. Results of the two-way ANOVA are summarized in Table 1. Significant effects of the dorsal ROIs were detected for FA, radial diffusivity, MTCSF and MTR. Post-hoc analyses revealed significant left-right differences in the dorsal spinal cord between C2 and C5 for both sessions (Figure 5). In the left dorsal segment, FA 
was decreased, axial diffusivity was unchanged, radial diffusivity was increased, MTCSF was increased and MTR was decreased. No significant left-right differences were detected laterally. No significant between-session differences were detected in the dorsal cord for FA $(P=0.06)$, axial diffusivity $(P=0.93)$, radial diffusivity $(P=0.37)$, MTCSF $(P=0.17)$, or MTR $(P=0.08)$.

\section{Discussion}

This is the first report of lengthy follow-up, detailed neurological testing, and advanced spinal cord imaging of a patient with apparent intramedullary injection during cervical ESI. We know of only 3 prior published cases [22,28]. In addition to immediate damage, the advanced MRI techniques used, including a new highly sensitive coil and multiple sequences able to distinguish white-matter degeneration from demyelination, revealed previously unreported delayed radiological changes most consistent with Wallerian degeneration of the injected ascending dorsal column. However, measurement of central motor conduction time (CMCT) after transcranial magnetic stimulation was the only test that identified the correlate of her motor deficits. CMCT demonstrated that the injury extended beyond the radiologically visualized lesion to involve the corticospinal tract; thus, radiological imaging alone may be insufficient to document the extent of such injuries.

Injecting into the spinal cord is universally contraindicated. Needlestick alone can cause injury, but in this case there was almost certainly additional injury from injectate, based on development of a cavitary lesion plus involvement of more than one spinal cord tract. Injectate can injure by mechanical disruption of nearby cells, chemical toxicity, and high osmolarity that triggers later disruption from edema. The small size of the cavity does not necessarily predict the volume of injectate within the spinal cord because radiological/ pathological correlations are unestablished. We considered which among the specific injections and injectates was causal. Intra-procedural fluoroscopy reportedly exonerated the contrast. The patient reportedly first complained of symptoms during local-anesthetic administration, but a $1.5^{\prime \prime}$ needle could not easily cause this lesion even with skin depression. A needle would have to traverse 2.26 " to cause a $1.6^{\prime \prime}$ deep injury, assuming a 45 degree caudal angle was used to penetrate between the angled spinous processes. Plus, local anesthetics acutely cause flaccid paresis, not the muscle spasms and increased tone documented. Thus the Depo-Medrol injection appears the most likely cause.

Intrathecal injections of various substances including water are often neurotoxic and have caused multiple cases of human paraparesis associated with both demyelination and axonal degeneration [17,20]. Depo-Medrol is explicitly contraindicated for intrathecal administration and is intermediate in neurotoxicity among tested preparations [2]. Pathological study demonstrates it can cause axonal and myelin degeneration plus disruption of the blood-nerve barrier when injected into peripheral nerves [31]; there are no data concerning effects of injection into brain or spinal cord. Depo-Medrol contains two other constituents in addition to methylprednisolone acetate. Polyethylene glycol is a watersoluble polymer used as a dispersant; low concentrations are non-toxic to nerve [3]. Benzyl alcohol (a-hydroxytoluene) is a bacteriostatic agent. When Depo-Medrol purified of its additives was intrathecally administered to dogs, this produced focal meningeal and intramedullary inflammation but no overt neuronal pathology [39], suggesting that the additives are more neurotoxic than the methylprednisolone. The radiological findings in this case are consistent with Depo-Medrol toxicity.

The new 32-channel receive coil, designed to maximize sensitivity in the cervical spinal cord, doubled the signal-to-noise ratio compared to standard commercial cervical spine coils [11]. To obtain the same signal-to-noise ratio using a commercial coil with half the 
sensitivity would require quadrupling acquisition time. The new coil enabled us to complete multiple high resolution sequences in a clinically feasible acquisition time (48 minutes). These revealed abnormal signal change most consistent with delayed Wallerian degeneration of ascending sensory tracts. Similar $\mathrm{T}_{2} *$ hyperintense signal was detected in the cervical cord of a patient with chronic spinal-cord injury using ultra-high field 7T MRI [12]. Since $T_{2}$ hyperintensity is not specific for pathological components, i.e. axon injury, myelin injury, or both [25,43], DTI and MT measures were performed to better characterize the white matter pathology. Animal $[4-6,10,26,27,30,43,44,54]$ and human $[8,13,35,46]$ studies of Wallerian degeneration suggest that changes in axial diffusivity are relatively specific for axonal degeneration and changes in radial diffusivity are relatively specific for demyelination. The schematic in Figure 6 illustrates these changes in DTI parameters at the acute, subacute and chronic phase of Wallerian degeneration, based on previous studies [30,54]. Acutely (hours to weeks), axonal fragmentation creates barriers to axial water mobility, reducing axial diffusivity. In the subacute through early-chronic phase (months to one year), activated microglia clear axonal debris, normalizing or even elevating axial diffusivity. In the late-chronic phase (years), astrocytic scarring can impede axial water mobility and decrease diffusivity. Radial diffusivity increases during the subacute to early chronic phase as myelin debris is cleared and it remains high during the late chronic phase. During all stages, the combined changes of axial diffusivity and radial diffusivity cause decreased FA, which is therefore less physiologically specific. Wallerian degeneration is very slow in the CNS, and can last up to 8 years [7].

In this patient, DTI at 8 and 12 months post-injury showed increased radial diffusivity (i.e, myelin breakdown), unchanged axial diffusivity (likely pseudonormalization after axon degeneration), and decreased FA in the left dorsal cord from C5 to C2, rostral to the C5-6 cavitary lesion. These DTI metrics most likely identify subacute to early chronic Wallerian degeneration. MT imaging evaluates interaction between the relatively immobile macromolecular (i.e., myelin) protons and mobile free-water protons [19,21,52]. MTR decreases in proportion to demyelination $[15,40]$. MTR measurements have been difficult in the cervical cord because of low signal-to-noise ratio and spinal cord movement during respiration. The alternative we used, CSF-normalized MT imaging (MTCSF), mitigates these [41]. However, it does not normalize for variations in spin density and $T_{1} / T_{2}$ relaxation times. If spin density, $\mathrm{T}_{1}$, and $\mathrm{T}_{2}$ are normal, then increased MTCSF reflects pure magnetization transfer effects that can be specifically attributed to demyelination. In this study, $\mathrm{T}_{2}$ - and $\mathrm{T}_{2}{ }^{*}$-weighted signal intensity were abnormal in the left dorsal cord, so the MTCSF hyperintensity might therefore reflect magnetization transfer, $\mathrm{T}_{2} /$ spin density, or both $[41,53]$. However, lower MTR at 51 weeks post-injury in the left dorsal cord confirmed magnetization transfer effects, suggesting demyelination. Thus, both DTI and MT imaging revealed demyelination in the left ascending dorsal cord, consistent with evolving Wallerian degeneration.

We also evaluated the utility of other non-radiological tests for this spinal cord injury. The normal results of electromyography and nerve conduction study served to exclude peripheral causes. Somatosensory evoked potentials, which assess the dorsal column/medial lemniscal pathway, were interpreted as normal. SSEP recordings are known to be relatively insensitive, and can remain normal in patients with significant sensory deficits or lesions, as here. However, abnormal SSEP results have high positive predictive value for somatosensory-tract lesions. Measurement of CMCT after transcranial magnetic stimulation was the most useful non-radiological test, providing the only objective correlate of the patient's persistent left-predominant corticospinal-tract damage (Figure 2). Previous studies reported excellent correlation between CMCT measurements and intramedullary MRI findings in patients with cervical spondylotic myelopathy [29] but here, CMCT study was more sensitive than even the most advanced MRI for detecting subtle corticospinal-tract 
abnormality. The current study suggests that advanced MRI techniques plus additional physiological diagnostic tests should be considered to more fully identify the extent of injury after focal cervical spinal cord injuries.

\section{Acknowledgments}

Funded in part by the Public Health Service; NIH-P41RR14075, NIH-K24NS59892, National Multiple Sclerosis Society [FG 1892A1/1]. Presented in abstract form to the 2011 meeting of the International Society for Magnetic Resonance in Medicine.

\section{References}

1. Abbasi A, Malhotra G, Malanga G, Elovic EP, Kahn S. Complications of interlaminar cervical epidural steroid injections: a review of the literature. Spine. 2007; 32(19):2144-2151. [PubMed: 17762818]

2. Benzon HT, Chew TL, McCarthy RJ, Benzon HA, Walega DR. Comparison of the particle sizes of different steroids and the effect of dilution: a review of the relative neurotoxicities of the steroids. Anesthesiology. 2007; 106(2):331-338. [PubMed: 17264728]

3. Benzon HT, Gissen AJ, Strichartz GR, Avram MJ, Covino BG. The effect of polyethylene glycol on mammalian nerve impulses. Anesth Analg. 1987; 66(6):553-559. [PubMed: 3578866]

4. Budde MD, Kim JH, Liang H-F, Russell JH, Cross AH, Song S-K. Axonal injury detected by in vivo diffusion tensor imaging correlates with neurological disability in a mouse model of multiple sclerosis. NMR Biomed. 2008; 21(6):589-597. [PubMed: 18041806]

5. Budde MD, Kim JH, Liang HF, Schmidt RE, Russell JH, Cross AH, Song SK. Toward accurate diagnosis of white matter pathology using diffusion tensor imaging. Magn Reson Med. 2007; 57(4): 688-695. [PubMed: 17390365]

6. Budde MD, Xie M, Cross AH, Song S-K. Axial diffusivity is the primary correlate of axonal injury in the experimental autoimmune encephalomyelitis spinal cord: a quantitative pixelwise analysis. $\mathrm{J}$ Neurosci. 2009; 29(9):2805-2813. [PubMed: 19261876]

7. Buss A, Brook GA, Kakulas B, Martin D, Franzen R, Schoenen J, Noth J, Schmitt AB. Gradual loss of myelin and formation of an astrocytic scar during Wallerian degeneration in the human spinal cord. Brain. 2004; 127(Pt 1):34-44. [PubMed: 14534158]

8. Cohen-Adad J, El Mendili M-M, Lehéricy S, Pradat P-F, Blancho S, Rossignol S, Benali H. Demyelination and degeneration in the injured human spinal cord detected with diffusion and magnetization transfer MRI. Neuroimage. 2011; 55(3):1024-1033. [PubMed: 21232610]

9. Cohen-Adad J, Gauthier CJ, Brooks JCW, Slessarev M, Han J, Fisher JA, Rossignol S, Hoge RD. BOLD signal responses to controlled hypercapnia in human spinal cord. Neuroimage. 2010; 50(3): 1074-1084. [PubMed: 20060914]

10. Cohen-Adad J, Leblond H, Delivet-Mongrain H, Martinez M, Benali H, Rossignol S. Wallerian degeneration after spinal cord lesions in cats detected with diffusion tensor imaging. Neuroimage. 2011; 57(3):1068-1076. [PubMed: 21596140]

11. Cohen-Adad J, Mareyam A, Keil B, Polimeni J, Wald LL. Optimized 32-Channel RF coil for brain, brainstem and cervical spinal cord at 3T. Magn Reson Med. 2011

12. Cohen-Adad J, Zhao W, Wald LL, Oaklander AL. 7T MRI of spinal cord injury. Neurology. (in press).

13. Concha L, Gross DW, Wheatley BM, Beaulieu C. Diffusion tensor imaging of time-dependent axonal and myelin degradation after corpus callosotomy in epilepsy patients. Neuroimage. 2006; 32(3):1090-1099. [PubMed: 16765064]

14. Derby R, Lee SH, Kim BJ, Chen Y, Seo KS. Complications following cervical epidural steroid injections by expert interventionalists in 2003. Pain Physician. 2004; 7(4):445-449. [PubMed: 16858486]

15. Dousset V, Grossman RI, Ramer KN, Schnall MD, Young LH, Gonzalez-Scarano F, Lavi E, Cohen JA. Experimental allergic encephalomyelitis and multiple sclerosis: lesion characterization with magnetization transfer imaging. Radiology. 1992; 182(2):483-491. [PubMed: 1732968] 
16. Dvorak J, Herdmann J, Janssen B, Theiler R, Grob D. Motor-evoked potentials in patients with cervical spine disorders. Spine. 1990; 15(10):1013-1016. [PubMed: 2263965]

17. Feasby TE, Hahn AF, Gilbert JJ. Neurotoxicity of bacteriostatic water. N Engl J Med. 1983; 308(16):966-967. [PubMed: 6687625]

18. Goel A, Pollan JJ. Contrast flow characteristics in the cervical epidural space: an analysis of cervical epidurograms. Spine. 2006; 31(14):1576-1579. [PubMed: 16778691]

19. Grossman RI, Gomori JM, Ramer KN, Lexa FJ, Schnall MD. Magnetization transfer: theory and clinical applications in neuroradiology. Radiographics. 1994; 14(2):279-290. [PubMed: 8190954]

20. Hahn AF, Feasby TE, Gilbert JJ. Paraparesis following intrathecal chemotherapy. Neurology. 1983; 33(8):1032-1038. [PubMed: 6688295]

21. Henkelman RM, Stanisz GJ, Graham SJ. Magnetization transfer in MRI: a review. NMR Biomed. 2001; 14(2):57-64. [PubMed: 11320533]

22. Hodges SD, Castleberg RL, Miller T, Ward R, Thornburg C. Cervical epidural steroid injection with intrinsic spinal cord damage. Two case reports. Spine. 1998; 2319:2137-2142. discussion 2141-2132. [PubMed: 9794061]

23. Huang RC, Shapiro GS, Lim M, Sandhu HS, Lutz GE, Herzog RJ. Cervical epidural abscess after epidural steroid injection. Spine. 2004; 29(1):E7-9. [PubMed: 14699291]

24. Jenkinson M, Bannister P, Brady M, Smith S. Improved optimization for the robust and accurate linear registration and motion correction of brain images. Neuroimage. 2002; 17(2):825-841. [PubMed: 12377157]

25. Kashani H, Farb R, Kucharczyk W. Magnetic resonance imaging demonstration of a single lesion causing Wallerian degeneration in ascending and descending tracts in the spinal cord. J Comput Assist Tomogr. 2010; 34(2):251-253. [PubMed: 20351516]

26. Kim JH, Budde MD, Liang HF, Klein RS, Russell JH, Cross AH, Song SK. Detecting axon damage in spinal cord from a mouse model of multiple sclerosis. Neurobiol Dis. 2006; 21(3):626632. [PubMed: 16298135]

27. Kozlowski P, Raj D, Liu J, Lam C, Yung AC, Tetzlaff W. Characterizing white matter damage in rat spinal cord with quantitative MRI and histology. J Neurotrauma. 2008; 25(6):653-676. [PubMed: 18578635]

28. Lee JH, Lee JK, Seo BR, Moon SJ, Kim JH, Kim SH. Spinal cord injury produced by direct damage during cervical transforaminal epidural injection. Reg Anesth Pain Med. 2008; 33(4):377379. [PubMed: 18675752]

29. Lo YL, Chan LL, Lim W, Tan SB, Tan CT, Chen JL, Fook-Chong S, Ratnagopal P. Systematic correlation of transcranial magnetic stimulation and magnetic resonance imaging in cervical spondylotic myelopathy. Spine. 2004; 29(10):1137-1145. [PubMed: 15131444]

30. Mac Donald CL, Dikranian K, Bayly P, Holtzman D, Brody D. Diffusion tensor imaging reliably detects experimental traumatic axonal injury and indicates approximate time of injury. $\mathrm{J}$ Neurosci. 2007; 27(44):11869-11876. [PubMed: 17978027]

31. Mackinnon SE, Hudson AR, Gentili F, Kline DG, Hunter D. Peripheral nerve injection injury with steroid agents. Plast Reconstr Surg. 1982; 69(3):482-490. [PubMed: 7063571]

32. McCreary CR, Bjarnason TA, Skihar V, Mitchell JR, Yong VW, Dunn JF. Multiexponential T2 and magnetization transfer MRI of demyelination and remyelination in murine spinal cord. Neuroimage. 2009; 45(4):1173-1182. [PubMed: 19349232]

33. Mottershead JP, Schmierer K, Clemence M, Thornton JS, Scaravilli F, Barker GJ, Tofts PS, Newcombe J, Cuzner ML, Ordidge RJ, McDonald WI, Miller DH. High field MRI correlates of myelin content and axonal density in multiple sclerosis--a post-mortem study of the spinal cord. J Neurol. 2003; 250(11):1293-1301. [PubMed: 14648144]

34. Neema M, Stankiewicz J, Arora A, Guss ZD, Bakshi R. MRI in Multiple Sclerosis: What's Inside the Toolbox? Neurotherapeutics. 2007; 4(4):602-617. [PubMed: 17920541]

35. Pierpaoli C, Barnett A, Pajevic S, Chen R, Penix LR, Virta A, Basser P. Water diffusion changes in Wallerian degeneration and their dependence on white matter architecture. Neuroimage. 2001; 13(6 Pt 1):1174-1185. [PubMed: 11352623] 
36. Pike GB, De Stefano N, Narayanan S, Worsley KJ, Pelletier D, Francis GS, Antel JP, Arnold DL. Multiple sclerosis: magnetization transfer MR imaging of white matter before lesion appearance on T2-weighted images. Radiology. 2000; 215(3):824-830. [PubMed: 10831705]

37. Reich DS, Smith SA, Zackowski KM, Gordon-Lipkin EM, Jones CK, Farrell JA, Mori S, van Zijl PC, Calabresi PA. Multiparametric magnetic resonance imaging analysis of the corticospinal tract in multiple sclerosis. Neuroimage. 2007; 38(2):271-279. [PubMed: 17870615]

38. Reitman CA, Watters W 3rd. Subdural hematoma after cervical epidural steroid injection. Spine. 2002; 27(6):E174-176. [PubMed: 11884923]

39. Rijsdijk M, van Wijck AJ, Kalkman CJ, Meulenhoff PC, Grafe MR, Steinauer J, Yaksh TL. Safety assessment and pharmacokinetics of intrathecal methylprednisolone acetate in dogs. Anesthesiology. 2012; 116(1):170-181. [PubMed: 22139590]

40. Schmierer K, Scaravilli F, Altmann DR, Barker GJ, Miller DH. Magnetization transfer ratio and myelin in postmortem multiple sclerosis brain. Ann Neurol. 2004; 56(3):407-415. [PubMed: 15349868]

41. Smith SA, Golay X, Fatemi A, Jones CK, Raymond GV, Moser HW, van Zijl PC. Magnetization transfer weighted imaging in the upper cervical spinal cord using cerebrospinal fluid as intersubject normalization reference (MTCSF imaging). Magn Reson Med. 2005; 54(1):201-206. [PubMed: 15968676]

42. Smith SM, Jenkinson M, Woolrich MW, Beckmann CF, Behrens TE, Johansen-Berg H, Bannister PR, De Luca M, Drobnjak I, Flitney DE, Niazy RK, Saunders J, Vickers J, Zhang Y, De Stefano N, Brady JM, Matthews PM. Advances in functional and structural MR image analysis and implementation as FSL. Neuroimage. 2004; 23 (Suppl 1):S208-219. [PubMed: 15501092]

43. Song SK, Sun SW, Ju WK, Lin SJ, Cross AH, Neufeld AH. Diffusion tensor imaging detects and differentiates axon and myelin degeneration in mouse optic nerve after retinal ischemia. Neuroimage. 2003; 20(3):1714-1722. [PubMed: 14642481]

44. Song SK, Yoshino J, Le TQ, Lin SJ, Sun SW, Cross AH, Armstrong RC. Demyelination increases radial diffusivity in corpus callosum of mouse brain. Neuroimage. 2005; 26(1):132-140. [PubMed: 15862213]

45. Sundgren PC, Dong Q, Gómez-Hassan D, Mukherji SK, Maly P, Welsh R. Diffusion tensor imaging of the brain: review of clinical applications. Neuroradiology. 2004; 46(5):339-350. [PubMed: 15103435]

46. Thomalla G, Glauche V, Koch MA, Beaulieu C, Weiller C, Rother J. Diffusion tensor imaging detects early Wallerian degeneration of the pyramidal tract after ischemic stroke. Neuroimage. 2004; 22(4):1767-1774. [PubMed: 15275932]

47. Trentman TL, Rosenfeld DM, Seamans DP, Hentz JG, Stanek JP. Vasovagal reactions and other complications of cervical vs. lumbar translaminar epidural steroid injections. Pain Practice. 2009; 9(1):59-64. [PubMed: 19019051]

48. van der Kouwe AJ, Benner T, Salat DH, Fischl B. Brain morphometry with multiecho MPRAGE. Neuroimage. 2008; 40(2):559-569. [PubMed: 18242102]

49. Waldman SD. Complications of cervical epidural nerve blocks with steroids: a prospective study of 790 consecutive blocks. Reg Anesth. 1989; 14(3):149-151. [PubMed: 2486595]

50. Waldman SD. Cervical epidural abscess after cervical epidural nerve block with steroids. Anesth Analg. 1991; 72(5):717-718. [PubMed: 2018238]

51. Wheeler-Kingshott C, Cercignani M. About "axial” and "radial” diffusivities. Magn Reson Med. 2009; 61(5):1255-1260. [PubMed: 19253405]

52. Wolff SD, Balaban RS. Magnetization transfer contrast (MTC) and tissue water proton relaxation in vivo. Magn Reson Med. 1989; 10(1):135-144. [PubMed: 2547135]

53. Zackowski KM, Smith SA, Reich DS, Gordon-Lipkin E, Chodkowski BA, Sambandan DR, Shteyman M, Bastian AJ, van Zijl PC, Calabresi PA. Sensorimotor dysfunction in multiple sclerosis and column-specific magnetization transfer-imaging abnormalities in the spinal cord. Brain. 2009; 132(Pt 5):1200-1209. [PubMed: 19297508]

54. Zhang J, Jones M, DeBoy CA, Reich DS, Farrell JA, Hoffman PN, Griffin JW, Sheikh KA, Miller MI, Mori S, Calabresi PA. Diffusion tensor magnetic resonance imaging of Wallerian 
degeneration in rat spinal cord after dorsal root axotomy. J Neurosci. 2009; 29(10):3160-3171. [PubMed: 19279253] 


\section{Summary}

Longitudinal multi-parametric MRI identified Wallerian degeneration in the spinal cord dorsal-column caused by inadvertent intramedullary injection. MRI was consistent with corticospinal central motor conduction time. 

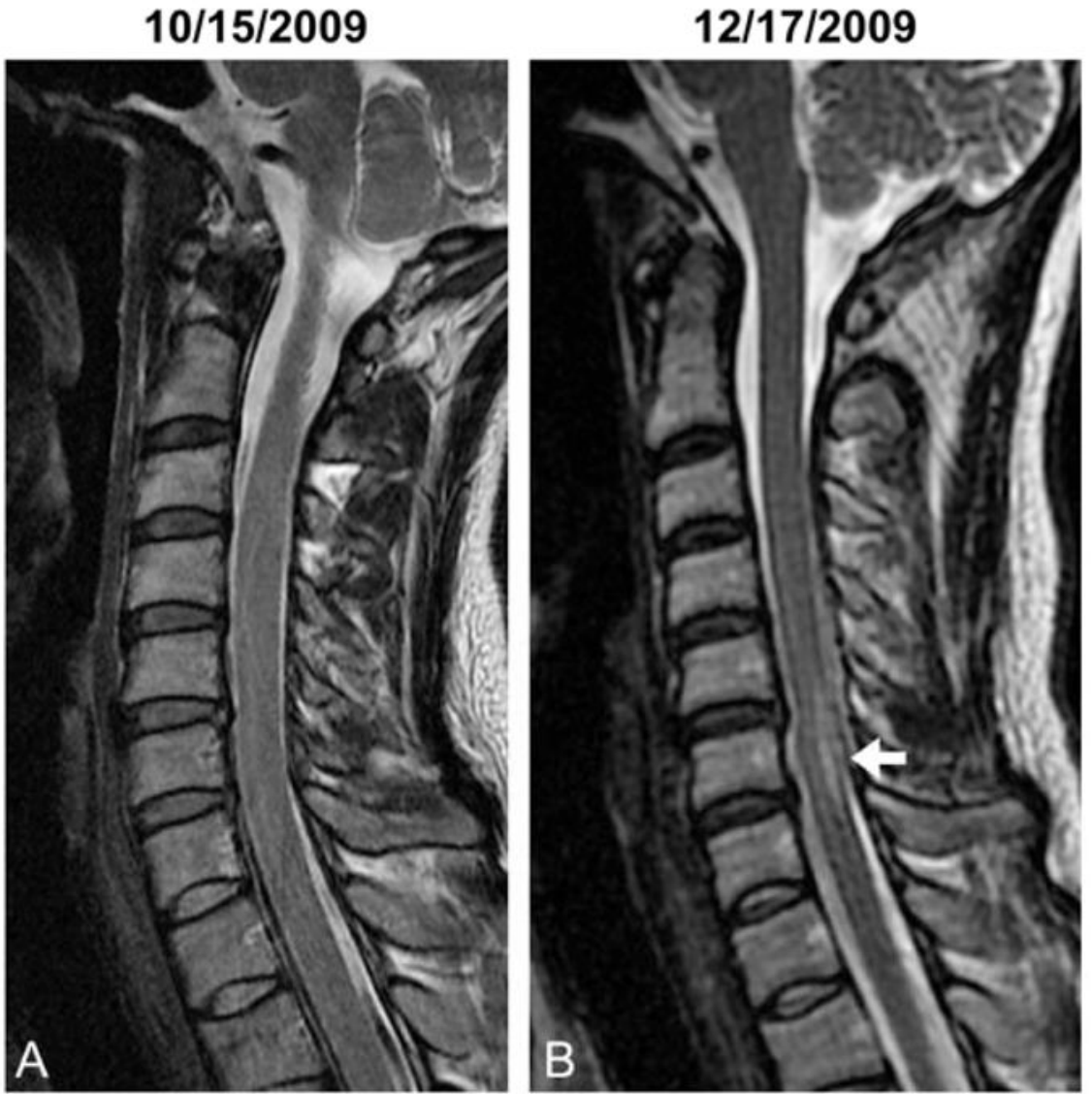

Figure 1.

Sagittal $\mathrm{T}_{2} \mathrm{~W}$ image of the cervical spinal cord (A) two months before cervical ESI shows small posterior disc protrusions at C5-6 and C6-7. Other images disclosed no evidence of significant cord or nerve root compression. Sagittal $\mathrm{T}_{2} \mathrm{~W}$ image $(\mathbf{B})$ one day after cervical ESI shows new linear $\mathrm{T}_{2}$ hyperintensity (arrow) within the dorsal aspect of the spinal cord from approximately C5-6 through C6-7. 

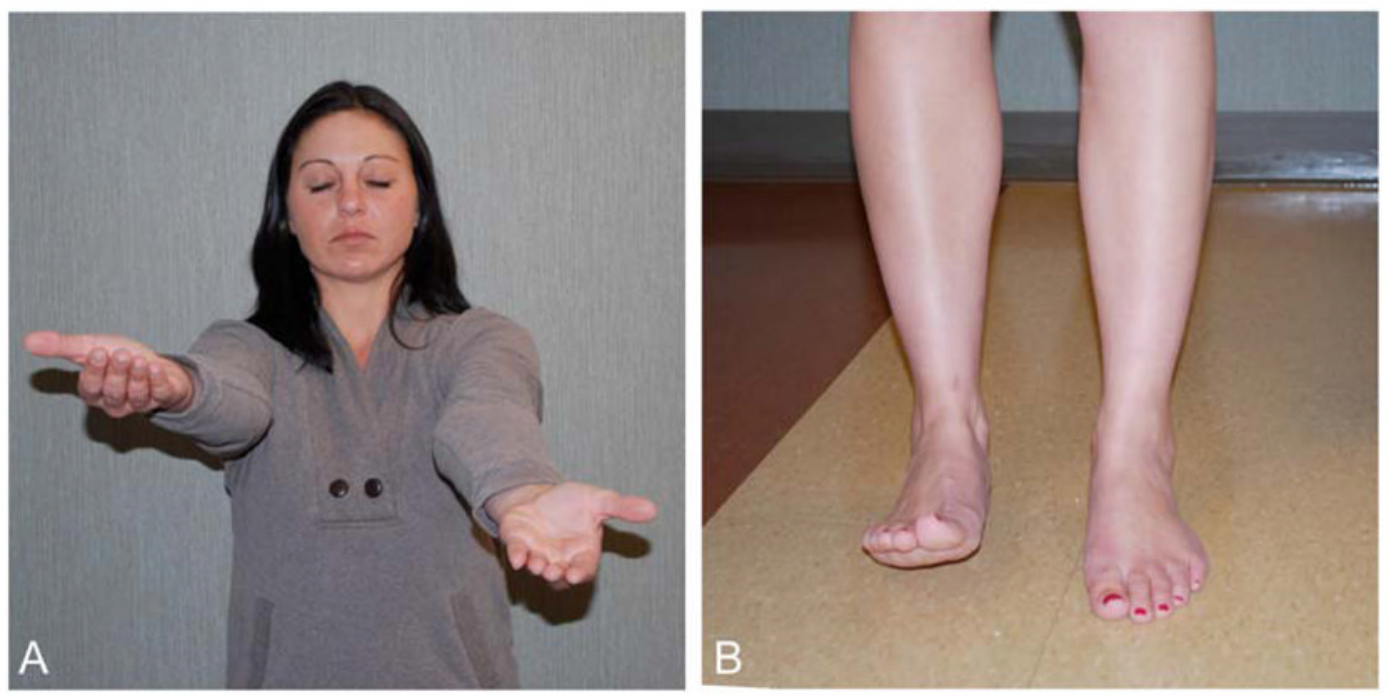

Figure 2.

This patient has mild persistent left hemiparesis affecting her arm and leg, as shown here 16 months post-SCI and persisting at 28 months post-SCI. Mild left-arm pronator drift (A), indicating relative left pyramidal (corticospinal) tract dysfunction. Continuing inability to dorsiflex the left ankle when asked to stand on both heels (B). She required an ankle-foot orthotic and single cane to walk. 


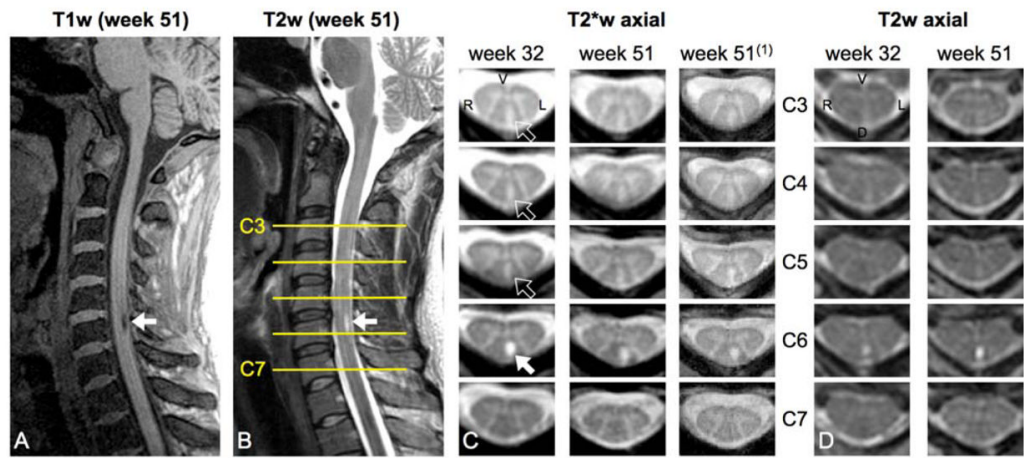

Figure 3.

Sagittal $\mathrm{T}_{1} \mathrm{w}$ image $(\mathbf{A})$, sagittal $\mathrm{T}_{2} \mathrm{w}$ image $(\mathbf{B})$, high resolution axial multiecho $\mathrm{T}_{2}{ }^{*} \mathrm{w}(\mathbf{C})$ and high resolution axial $\mathrm{T}_{2} \mathrm{w}(\mathbf{D})$. Cord $\mathrm{T}_{1}$ hypointensity and $\mathrm{T}_{2} / \mathrm{T}_{2} *$ hyperintensity at $\mathrm{C} 6$ (solid arrows) suggest tissue loss. Cord $\mathrm{T}_{2} / \mathrm{T}_{2} *$ hyperintensity at $\mathrm{C} 5, \mathrm{C} 4$, and $\mathrm{C} 3$ (outline arrows), but not at $\mathrm{C} 7$, suggest Wallerian degeneration of the ascending dorsal-column somatosensory tract. ${ }^{(1)}$ At week 51 , a very high resolution multiecho $\mathrm{T}_{2}{ }^{*} \mathrm{w}$ sequence was acquired $\left(0.3 \times 0.3 \mathrm{~mm}^{2}\right.$ in-plane $)$ to further improve characterization of the lesion extent. Slight image blurring on the second scan is attributed to patient motion. 

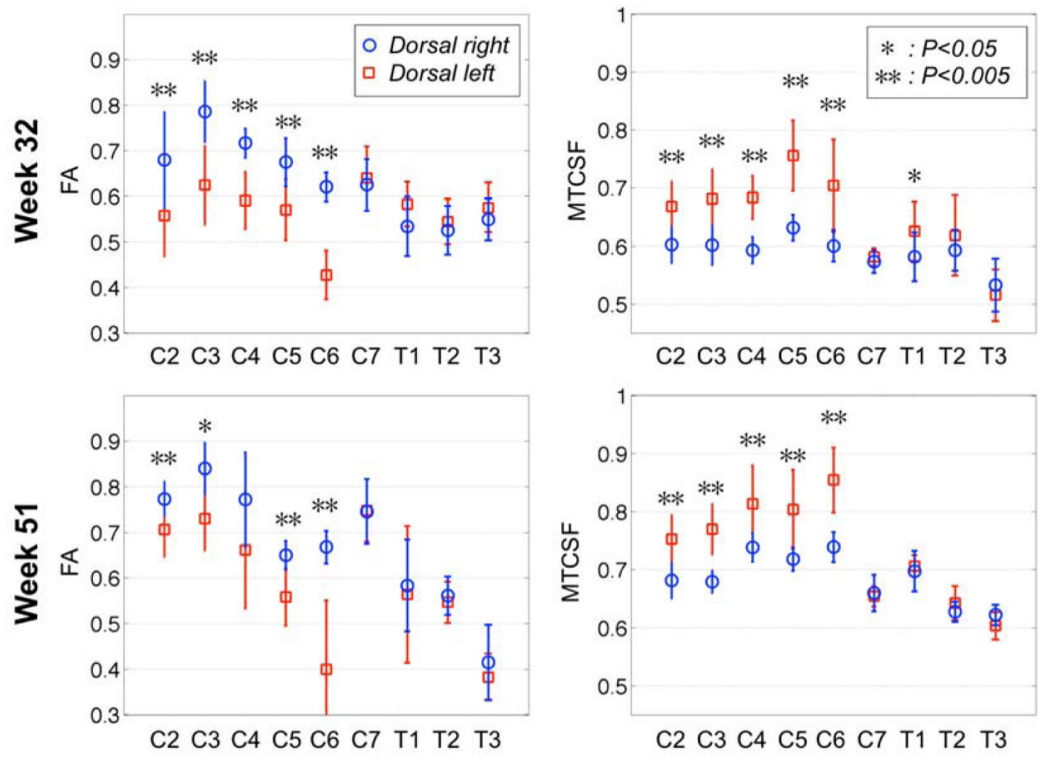

Figure 4.

Quantification of FA and MTCSF along the dorsal spinal cord from C2 to T3 vertebral levels at week 32 and week 51. Error bars represent the standard deviation within one vertebral level. Significant FA reduction and MTCSF increase are detected at and rostral to the lesion. At week 51 FA and MTCSF values are slightly higher, which could be attributed to differences in flip angle, patient motion and partial volume effects. 
A
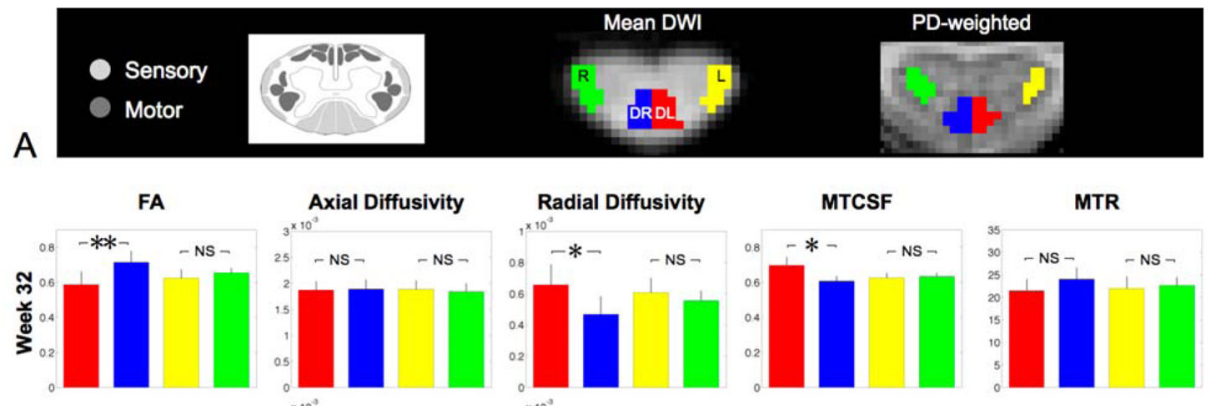

Axial Diffusivity

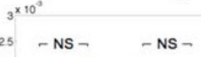

Radial Diffusivity
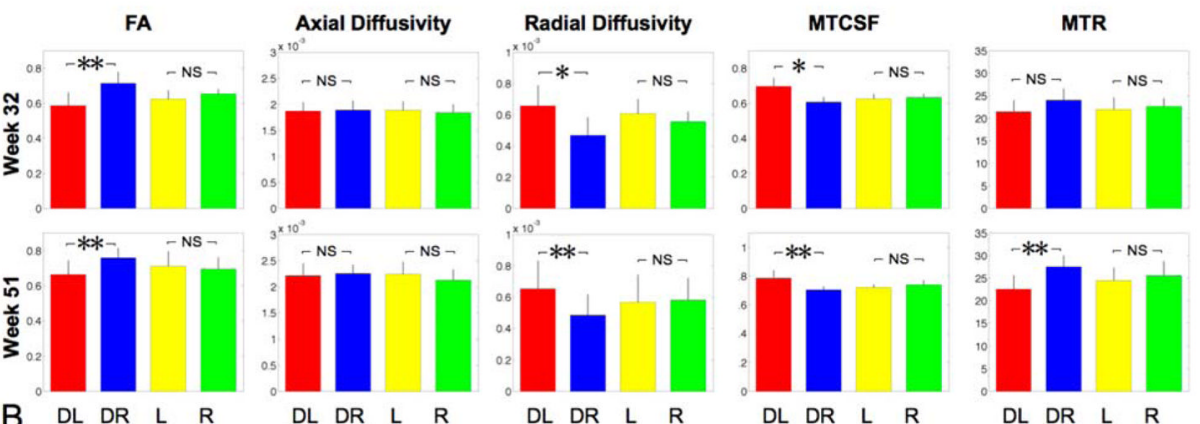

DL DR L R

DL DR L R

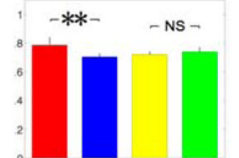

DL DR $L \quad R$

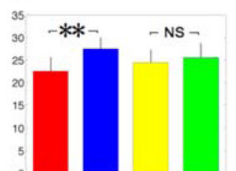

DL DR L R

Figure 5.

ROIs defined on the mean DWI and on the axial proton density (PD) weighted image (A). ROIs were delineated on the dorsal left (DL), dorsal right (DR), left (L) and right (R) portions of the spinal cord rostral to the cavity, i.e., from C2 to C5. Mean +/- standard deviation across slices for DTI and MT metrics (B). Two-tailed Student's $t$-test paired for vertebral levels tested the effect of laterality (right versus left ROIs). Tests were Bonferronicorrected for comparison between the two sessions. *: $P<0.05, * *: P<0.005$, NS: NonSignificant. 


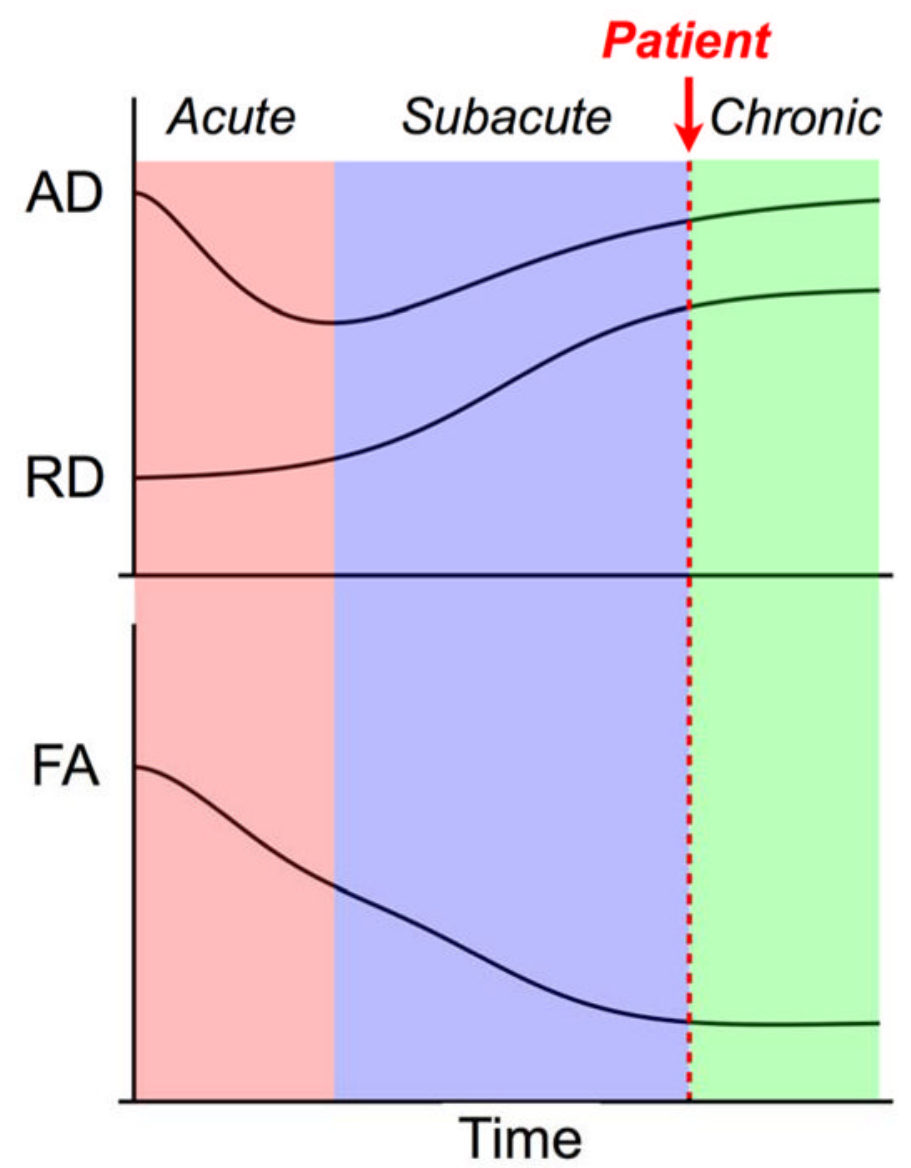

Figure 6.

Schematic depicting how DTI metrics change with time after injury. Radial diffusivity (RD) and axial diffusivity (AD) provide more specificity to various stages of white matter pathology compared to fractional anisotropy (FA). 


\section{Table 1}

$P$-values resulting from the two-way ANOVA. The independent variables were: regions of interest (ROIs) (dorsal left, dorsal right) and session (week 32 and week 51 post-injury). Metrics were quantified from vertebral levels C2 to C5. Differences for the ROIs are seen for the FA, radial diffusivity, MTCSF and MTR.

\begin{tabular}{llll}
\hline & ROIs & Sessions & ROI* Session \\
\hline FA & $0.0038^{* *}$ & 0.0723 & 0.6010 \\
Axial Diffusivity & 0.8313 & $0.0348^{*}$ & 0.9537 \\
Radial Diffusivity & $0.0264^{*}$ & 0.9197 & 0.8903 \\
MTCSF & $0.0001^{* *}$ & $0.0000^{* *}$ & 0.7569 \\
MTR & $0.0007^{* *}$ & $0.0175^{*}$ & 0.1745 \\
\hline${ }^{*} P<0.05$, & & & \\
${ }^{* *} P<0.005$. & & \\
$P$-values are truncated after the fourth decimal. &
\end{tabular}

